DOI: 10.15587/2706-5448.2021.235471

Article type «Reports on Research Projects»

\section{Anna Krvavych, Roksolana Konechna}

\title{
OPTIMIZATION OF PARAMETERS OF THE EXTRACTION PROCESS OF BIOLOGICALLY ACTIVE SUBSTANCES OF GRASS ADONIS VERNALIS
}

The object of this research is the herb Adonis vernalis and hydroalcoholic extracts obtained on its basis. By the nature of the action, the drugs Adonis vernalis belong to the group of cardiac glycosides and occupy an intermediate place between strophanthin and digitalis. In official medicine, biologically active compounds of Adonis vernalis are included in drugs such as Cardiovalen, Adonis-bromine, Caridiolin and Cardiophyte. In the extemporal formulation, the extract is part of the Bechterew's medicine. Until recently, scientists have made significant progress in studying the phytochemical and pharmacological action of the herb Adonis vernalis. However, one should not be limited to the use of Adonis vernalis only for stimulating cardiac activity, one should also consider the promising antioxidant effect of flavonoids and phenolic compounds that are contained in this medicinal plant. Also, studies of the extraction conditions of the herb Adonis vernalis are not described in the scientific literature.

The study carried out the extraction of the grass Adonis vernalis by various methods (static and dynamic). The type of extract was chosen as the most rational, which provides the maximum yield of extractives (phenolic compounds and cardiac glycosides). For this, the optimal extraction conditions were selected, namely, the particle size, the type of extractant, the value of the hydromodule and the extraction method. Accordingly, the optimal particle diameter for maximum extraction of biologically active substances of the herb Adonis vernalis is $2.5 \mathrm{~mm}$, the optimal extractant is $70 \%$ ethyl alcohol, the ratio of raw materials: extractant is 1:10, the optimal extraction method is maceration with constant stirring. Phytochemical studies of the quantitative composition of the main groups of biologically active substances were carried out using calorimetric and spectrophotometric methods of analysis.

As a result of the optimization of the process and its introduction into production on an industrial scale, the value added effect will be achieved. And also a high-quality product has been created that will compete with broad-spectrum drugs already existing on the market.

Keywords: flavonoids, cardiac glycosides, phenolic compounds, Adonis vernalis, extraction process, optimal conditions, extraction method.

\section{How to cite}

Krvavych, A., Konechna, R. (2021). Optimization of parameters of the extraction process of biologically active substances of grass Adonis vernalis. Technology Audit and Production Reserves, 3 (3 (59)), 14-18. doi: http://doi.org/10.15587/2706-5448.2021.235471

\section{Introduction}

The consumption of medicinal products based on medicinal plants is growing rapidly worldwide. According to the World Health Organization (WHO), about $80 \%$ of the world's population use medicinal plants to treat various diseases. According to WHO experts, in the next 10 years, the share of phytopreparations in the total consumption of pharmaceuticals will amount to $60 \%$ [1, 2]. Medicinal plant raw materials (MPRM) Adonis vernalis contains:

- cardiac glycosides (cymarine, adonitoxin, 16-hydroxystrophantidine, acetate-palonitoxin, vernadigin, 3-acetylstrophadogenin, strophantidine fucoside, 3-epiperiplogenin, digitoxigenin);

glycosides (adonilide, fucuyusonorone, fucuyuson, lineolone, 12-B-benzoylisolineolone, nicotinoilisoramanon, isoramanon);
- phenolic compounds;

- flavonoids (adonivertin, homoadonivertin, orientin, homoorientin, isoorientin, luteolin, vitexin);

- quinones;

- saponins;

- coumarins, etc.

Biologically active compounds (BAS) Adonis vernalis have a beneficial effect on the cardiovascular system, have antiangiogenic, antibacterial, antiblastoma, sedative, antioxidant, anti-inflammatory, antiviral, diuretic, analgesic and acaricidal activity [3-5].

Extraction of medicinal raw materials is widely used in the preparation of various preparations of natural compounds. The completeness of the extraction of natural compounds from medicinal raw materials significantly affects the choice of the extractant, which is determined by the properties of the extracted substances, as well as the type 
of the obtained preparation (liquid extract or dry extract, or an individual substance). The process of extracting dried plant materials begins with the penetration of the extractant into the material, wetting the substances inside the cell, and then their dissolution and desorption, diffusion through the pores of the cell membrane, ends with the mass transfer of substances from the surface of the material into the solution.

Despite a wide variety of scientific works devoted to ways to increase the efficiency of extraction, as well as the introduction of new technologies into practice aimed at optimizing the processes of extracting biologically active substances from medicinal plant raw materials, the question of further research in this area remains open.

So, the objects of research were the herb Adonis vernalis and the hydroalcoholic extracts obtained on its basis.

The aim of research is to determine the optimal conditions for the extraction, obtain dry extracts from the herb Adonis vernalis and their phytochemical analysis for the content of biologically active substances.

\section{Methods of research}

The experiment was carried out with previously prepared grass Adonis vernalis. The raw material was purified from impurities and mechanical impurities, the determination of the content of impurities was carried out in accordance with the requirements of the State Pharmacopoeia of Ukraine (SPU) [6, article 2.8.2]. Using sieves of various hole diameters $(0.5,1.0,1.6,2.5$ and $4 \mathrm{~mm})$, the raw material was divided into fractions. For extraction, $10 \mathrm{~g}$ of crushed raw materials were poured into a $250 \mathrm{ml}$ round-bottom flask, and $100 \mathrm{ml}$ of ethyl alcohol (EtOH) of the appropriate concentration was poured. The process was carried out with constant stirring using a magnetic stirrer at five different temperatures $\left(20,25,30,40\right.$ and $\left.50{ }^{\circ} \mathrm{C}\right)$ for 6 hours for each specific average particle size $(0.5,1.0,1.6,2,5$ and $4.0 \mathrm{~mm}$ ). After each extraction process, the solvent was removed at the boiling point of the corresponding extractant. The experiment, carried out on any set of conditions, was carried out three times and the average value was recorded. The yield of extractive substances $D(\%)$ from the extracted plant material was calculated by the formula:

$$
D=\frac{\omega \cdot V}{m_{c}}
$$

where $V$ - total volume of the obtained extract, $\mathrm{ml} ; \omega$ - dry residue in the obtained extract, $\% ; m_{c}$ - mass of plant material used for extraction, g.

2.1. Method for studying the content of flavonoids in the extract. The total content of flavonoids in the extract was estimated by the colorimetric method with aluminum chloride $\mathrm{AlCl}_{3}$ [7]. According to this method, quercetin was used as a standard, which was expressed as quercetin equivalent (QE). A standard curve of known concentrations of quercetin was constructed by preparing and testing five concentrations of a standard solution of quercetin, which were $0,25,50,75$ and $100 \mathrm{mg} / \mathrm{l}$. A stock solution of quercetin was prepared by dissolving $25 \mathrm{mg}$ of quercetin in $100 \mathrm{ml}$ of $80 \%$ ethanol. Then standard working solutions were prepared by pipetting aliquots of $0,1,2,3$ and $4 \mathrm{ml}$ of the stock solution $(250 \mathrm{mg} / \mathrm{L})$ into $10 \mathrm{ml}$ volumetric flasks and adjusting the volume with $80 \%$ ethanol. Using test tubes, $1 \mathrm{ml}$ of each standard solution was reacted with $3 \mathrm{ml}$ of $95 \%$ ethanol, $0.2 \mathrm{ml}$ of a $10 \%$ aqueous dilution of the $\mathrm{AlCl}_{3}$ reagent, $0.2 \mathrm{ml}$ of $1 \mathrm{M}$ potassium acetate, and $5.6 \mathrm{ml}$ of distilled water. The mixture was thoroughly mixed with a vortex mixer for $30 \mathrm{~s}$ and kept at room temperature for 30 minutes. Absorption readings were performed using an ultraviolet (UV)/visible spectrophotometer «Hitachi U-2810» (Japan) at $415 \mathrm{~nm}$.

Preparation of test samples: $5 \mathrm{~g}$ of each test sample was dissolved in $25 \mathrm{ml}$ of $80 \%$ methanol. $1 \mathrm{ml}$ of each sample solution was transferred to a test tube. Subsequently, similar procedures used to construct the standard curve were used to analyze $1 \mathrm{ml}$ of each of the standard solutions. For each sample, a blank for the sample was prepared similarly, but the same amount of a $10 \% \mathrm{AlCl}_{3}$ solution $(0.2 \mathrm{ml})$ was replaced with distilled water. Absorbance readings were taken with a Hitachi U-2810 UV/Vis spectrophotometer at $415 \mathrm{~nm}$. The content of the sum of flavonoids in terms of quercetin and absolutely dry raw material $A$, \%, was calculated by the formula:

$$
A=\frac{D \cdot m_{0} \cdot 100 \cdot 100 \cdot 100}{D_{0} \cdot m \cdot 100 \cdot(100-W)}
$$

where $D$ - optical density of the solution used; $D_{0}-$ optical density of the pharmacopoeial sample of quercetin; $m$ - mass of the raw material, g; $m_{0}$ - mass of the pharmacopoeial sample of quercetin, g; $W$ - loss in mass during drying of raw materials, \%.

2.2. Technique for studying the content of phenolic compounds in the extract. The total content of phenols in the extract samples was determined by the Folin-Ciocalteu method [8]. Standard preparation: To calculate the total phenol content, which was expressed as gallic acid equivalent (GAE), a standard curve of known gallic acid concentrations was constructed. Standard solutions were prepared in five different concentrations, which represent 0, 25, 50, 75 and $100 \mathrm{mg} / \mathrm{l}$. A basic gallic acid solution was prepared by dissolving $25 \mathrm{mg}$ of gallic acid in $100 \mathrm{ml}$ of $70 \%$ methanol. Then, to prepare standard working solutions of $0,1,2,3$, and $4 \mathrm{ml}$, aliquots of the stock gallic acid solution $(250 \mathrm{mg} / \mathrm{l})$ separately pipette into a $10 \mathrm{ml}$ volumetric flask and subsequently diluted to a volume of $70 \%$ methanol.

To form a standard curve, $1 \mathrm{ml}$ of each of the standard solutions are pipetted into a separate tube. Then $5 \mathrm{ml}$ of $10 \%$ aqueous dilution of Folin-Ciocalteu reagent was added and mixed well with a vortex mixer for $1 \mathrm{~min}$. After 3-8 min, $4 \mathrm{ml}$ of $75 \mathrm{~g} / \mathrm{l}$ anhydrous $\mathrm{Na}_{2} \mathrm{CO}_{3}$ solution was added. The mixture was thoroughly stirred for another $1 \mathrm{~min}$ and kept in a water bath at $45{ }^{\circ} \mathrm{C}$ for $15 \mathrm{~min}$.

Preparation of the test samples: $5 \mathrm{~g}$ of each sample of the obtained extract was dissolved in $50 \mathrm{ml}$ of $70 \%$ methanol $1 \mathrm{ml}$ of each methanol sample solution was transferred into a test tube. Then it was processed and measured according to the procedure that was used to construct the standard curve.

For each extract sample, a sample blank was prepared by pipetting $20 \mathrm{ml}$ of the extract sample into a $100 \mathrm{ml}$ glass beaker and adjusting the $\mathrm{pH}$ to 3.5 by adding $20 \%$ acetic acid. After adding $1.6 \mathrm{~g}$ of polyvinylpolypyrrolidone (PVPP), the extract was gently shaken by hand 
at $320 \mathrm{rpm}$ for 20 minutes. The PVPP mixture was filtered through filter paper \#1, and $1 \mathrm{ml}$ of the filtrate was taken and tested as described above. After cooling, the absorbances of the standards, sample solutions and references were read in a Hitachi U-2810 UV/VIS spectrophotometer at $765 \mathrm{~nm}$ against a zero absorbent blank. To calculate the final content of total phenolic acid $(B)$, the following formula was used:

$$
B=\frac{\left(D_{\text {sample }}-D_{\text {insert }}\right) \cdot V_{\text {sample }} \cdot d \cdot 100}{S_{\text {std }} \cdot m_{\text {sample }} \cdot 10^{3} \cdot \omega_{D M \text { sample }}},
$$

where $D_{\text {sample }}$ - optical density of the solution; $D_{\text {insert }}$ - optical density, which corresponds to the point of intersection of the calibration curve with the $y$-axis; $V_{\text {sample }}$ - extract volume, $\mathrm{cm}^{3} ; d$-dilution factor; $S_{s t r}$ - tangent of the inclination angle of the calibration straight line; $m_{\text {sample }}-$ mass of the sample, g; $\omega_{D M \text {,sample }}$ - loss in mass during drying of raw materials, \%.

To optimize the extraction process, the following extraction methods were used: maceration (infusion), remaceration (fractional maceration) and maceration with constant stirring.

According to the results obtained, $70 \%$ ethyl alcohol was used as the extractant, $M$ was $1: 10$, the degree of grinding of the medicinal plant was $1.6 \mathrm{~mm}$. With the method of maceration (infusion), the crushed medicinal raw material was poured with alcohol and left for 6 hours, stirring was carried out at the beginning and at the end of the experiment. After infusion, the extract was filtered through a paper filter.

During remaceration (fractional maceration), extraction was performed using a Soxhlet apparatus. The extraction was carried out at a temperature of $78.39^{\circ} \mathrm{C}$ for $6 \mathrm{~h}$.

Extraction by maceration with constant stirring was carried out at room temperature for $6 \mathrm{~h}$. After extraction, each extract was concentrated in vacuum to obtain a dry extract with a moisture content of up to $5 \%$.

The efficiency of the extraction methods was determined by the yield of extractives. The quantitative content of extractives was carried out by the spectrophotometric method.

\section{Research results and discussion}

According to the formula (1), the calculations of the yield of extractive substances from the extracted plant raw material were performed, the results of which are presented in Tables 1, 2 and in Fig. 1, 2.

According to the experimental results (Table 1, Fig. 1), the maximum BAS yield is achieved upon extraction with $70 \% \mathrm{EtOH}$. This result can be explained by the structure of the extracted BAS, namely, by the presence of hydroxyl groups. At an extractant concentration of $70 \%$, the desorption and solvation properties of EtOH are combined. The polarity and penetrating properties of $70 \% \mathrm{EtOH}$ allow to influence all stages of extraction, provide the processes of internal, molecular and convective diffusion, which is accompanied by the interphase distribution of compounds [9-11].

Table 1

Effect of the extractant on the yield of extractive substances, the amount of cardiac glycosides and the amount of flavonoids from the herb Adonis vernalis

\begin{tabular}{|c|c|c|c|}
\hline Extractant & $\begin{array}{c}\text { Flavonoid } \\
\text { yield, \% }\end{array}$ & $\begin{array}{c}\text { Cardiac glyca- } \\
\text { sides yield, \% }\end{array}$ & $\begin{array}{c}\text { Phenolic com- } \\
\text { pounds yield, \% }\end{array}$ \\
\hline Water & $0.65 \pm 0.17$ & $0.22 \pm 0.03$ & $3.01 \pm 0.11$ \\
\hline $40 \% \mathrm{EtDH}$ & $0.71 \pm 0.10$ & $0.61 \pm 0.05$ & $3.78 \pm 0.07$ \\
\hline $50 \% \mathrm{EtOH}$ & $0.88 \pm 0.01$ & $0.64 \pm 0.01$ & $3.81 \pm 0.07$ \\
\hline $60 \% \mathrm{EtDH}$ & $0.92 \pm 0.04$ & $0.66 \pm 0.09$ & $3.85 \pm 0.07$ \\
\hline $70 \% \mathrm{EtDH}$ & $1.22 \pm 0.07$ & $0.72 \pm 0.07$ & $3.92 \pm 0.17$ \\
\hline $80 \% \mathrm{EtDH}$ & $1.01 \pm 0.17$ & $0.71 \pm 0.03$ & $3.85 \pm 0.07$ \\
\hline $90 \% \mathrm{EtDH}$ & $1.06 \pm 0.17$ & $0.70 \pm 0.01$ & $3.81 \pm 0.04$ \\
\hline
\end{tabular}

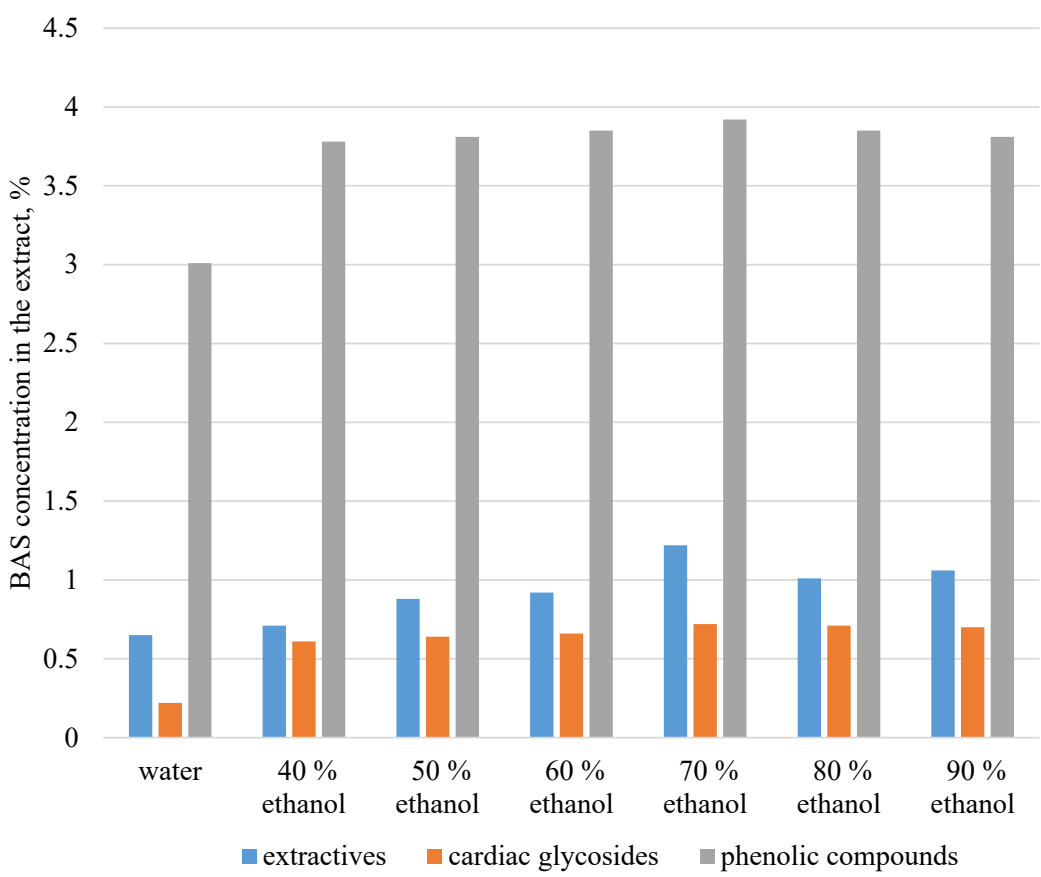

Fig. 1. Influence of the extractant on the yield of extractives

Table 2

Influence of the grinding degree of raw materials on the yield of flavonoids, cardiac glycosides and the amount of phenolic compounds from the herb Adonis vernalis

\begin{tabular}{|c|c|c|c|}
\hline \multirow{2}{*}{$\begin{array}{c}\text { Grinding } \\
\text { degree, } \\
\text { mm }\end{array}$} & \multicolumn{3}{|c|}{ Yield in terms of air-dry raw materials, \% } \\
\cline { 2 - 4 } & Flavonoid yield, \% & $\begin{array}{c}\text { Cardiac glycosides } \\
\text { yield, \% }\end{array}$ & $\begin{array}{c}\text { Phenolic com- } \\
\text { pounds yield, \% }\end{array}$ \\
\hline 0.5 & $0.91 \pm 0.20$ & $0.54 \pm 0.11$ & $3.79 \pm 0.97$ \\
\hline 1.0 & $0.98 \pm 0.21$ & $0.64 \pm 0.04$ & $3.88 \pm 0.44$ \\
\hline 1.6 & $0.92 \pm 0.24$ & $0.67 \pm 0.07$ & $3.92 \pm 1.07$ \\
\hline 2.5 & $1.22 \pm 0.07$ & $0.71 \pm 0.09$ & $3.76 \pm 0.33$ \\
\hline 4.0 & $1.21 \pm 0.04$ & $0.67 \pm 0.04$ & $3.64 \pm 1.02$ \\
\hline
\end{tabular}




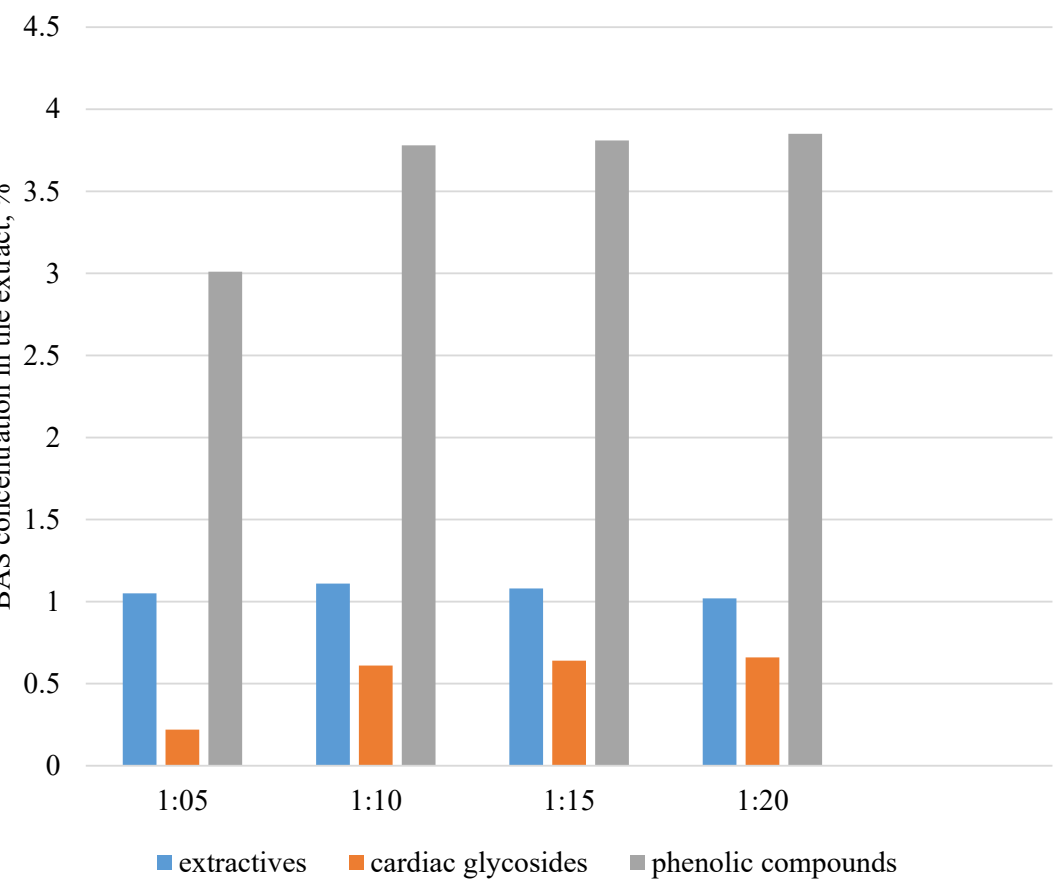

Fig. 2. Influence of the grinding degree of raw materials on the yield of extractives

The optimum degree of grinding at which the maximum extraction of flavanoids, cardiac glycosides and the sum of phenolic compounds is achieved is $2.5 \mathrm{~mm}$ (Table 2, Fig. 2). This is due to the increased contact surface for better extraction.

With further grinding, a decrease in the content of biologically active substances is observed, which can be explained by an increase in ballast substances in the extract.

The results of calculating the final content of total phenolic acid according to the formula (2) are presented in Table 3 and Fig. 3.
Table 3

The yield of extractives depending on the ratio of the phases raw material/extractant

\begin{tabular}{|c|c|c|c|}
\hline \multirow{2}{*}{$\begin{array}{c}\text { Raw material/ex- } \\
\text { tractant ratio }\end{array}$} & \multicolumn{3}{|c|}{ Yield in terms of air-dry raw materials, \% } \\
\cline { 2 - 4 } & $\begin{array}{c}\text { Flavonoid } \\
\text { yield, \% }\end{array}$ & $\begin{array}{c}\text { Cardiac glyco- } \\
\text { sides yield, \% }\end{array}$ & $\begin{array}{c}\text { Phenolic com- } \\
\text { pounds yield, \% }\end{array}$ \\
\hline $1: 5$ & $1.05 \pm 0.07$ & $0.22 \pm 0.03$ & $3.01 \pm 0.11$ \\
\hline $1: 10$ & $1.11 \pm 0.10$ & $0.61 \pm 0.05$ & $3.78 \pm 0.07$ \\
\hline $1: 15$ & $1.08 \pm 0.01$ & $0.64 \pm 0.01$ & $3.81 \pm 0.07$ \\
\hline $1: 20$ & $1.02 \pm 0.04$ & $0.66 \pm 0.09$ & $3.85 \pm 0.07$ \\
\hline
\end{tabular}

4.5

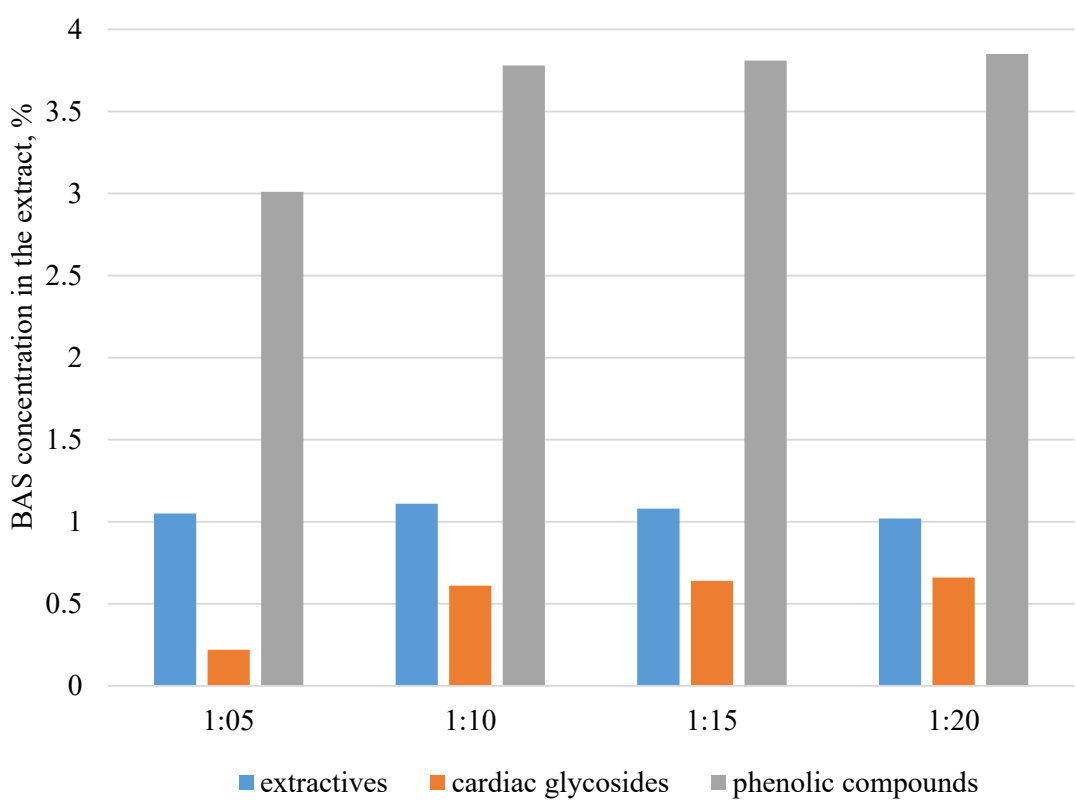

Fig. 3. The yield of extractives depending on the ratio of the phases raw material/extractant 
The transition of a substance from a solid to a liquid phase occurs only before reaching a state of equilibrium between the phases, which is considered as the final stage of the extraction process. Under equilibrium conditions, the concentration of the target substances in the extract filling the free space of the solid phase must correspond to a certain equilibrium concentration of these substances in the main volume of the extractant. It was found that this concentration is achieved at a phase ratio of $1: 15$.

The results of calculating the final content of total phenolic acid according to the formula (3) are presented in Table 4.

Table 4

The quantitative content of extractives in the dry extract of the herb Adonis vernalis

\begin{tabular}{|c|l|c|}
\hline No. & \multicolumn{1}{|c|}{ Extraction method } & $\begin{array}{c}\text { Content of extractive } \\
\text { substances, \% }\end{array}$ \\
\hline 1 & Maceration (infusion) & $8.91 \pm 0.19$ \\
\hline 2 & Remaceration (fractional maceration) & $14.77 \pm 0.31$ \\
\hline 3 & Maceration with constant stirring & $20.41 \pm 0.27$ \\
\hline
\end{tabular}

As a result of the studies, it has been found that the optimal method for extracting the herb Adonis vernalis is maceration with constant stirring (Table 4).

The resulting extract is a dry extract of Adonis vernalis, an amorphous brown powder with a specific odor, with a moisture content of up to $5 \%$.

\section{Conclusions}

The studies carried out made it possible to determine the optimal values of the parameters affecting the process of extracting biologically active substances from the herb Adonis vernalis. Among which are the degree of grinding of raw materials, the selection of the extractant, the ratio of the raw material and the extractant (hydromodule).

Based on the results of determining the content of biologically active substances in the obtained samples, the optimal parameters of the degree of grinding of raw materials $d=2.5 \mathrm{~mm}$ were selected, the extractant, which maximally excludes BAS, was $70 \% \mathrm{EtOH}$ with a raw material: extractant ratio of 1:10.

Based on the study of the properties of raw materials and the extraction process, the method of maceration with constant stirring was chosen as the most optimal for the extraction of the herb Adonis vernalis.

\section{References}

1. Orhan, I. E., Gokbulut, A., Senol, F. S. (2017). Adonis sp., Convallaria sp., Strophanthus sp., Thevetia sp., and Leonurus sp. - Cardiotonic Plants with Known Traditional Use and a Few Preclinical and Clinical Studies. Current Pharmaceutical Design, 23 (7), 1051-1059. doi: http://doi.org/10.2174/1381612822666161010104548

2. Hershtun, A. O., Petrina, R. O. (2016). Vyroshchuvannia horytsvitu vesnianoho (Adonis Vernalis) v umovakh in vitro. Khimiia, tekhnolohiia ta zastosuvannia rechovyn, 841 (80), 133-137.

3. Chernobai, V. T., Komissarenko, N. F., and Litvinenko, V. I. (1968). Structure of flavonoid glycoside from Adnois vernalis. Khim. Prir. Soedin., 4, 51.

4. Gostin, I. N. (2011). Anatomical and micromorphological peculiarities of Adonis vernalis L. (Ranunculaceae). Pakistan Journal of Botany, 43, 811-820.

5. Kim, S.-J., Pham, T.-H., Bak, Y., Ryu, H.-W., Oh, S.-R., Yoon, D.-Y. (2018). Orientin inhibits invasion by suppressing MMP-9 and IL-8 expression via the PKC $\alpha$ /ERK/AP-1/STAT3mediated signaling pathways in TPA-treated MCF-7 breast cancer cells. Phytomedicine, 50, 35-42. doi: http://doi.org/ 10.1016/j.phymed.2018.09.172

6. Derzhavna Farmakopeia Ukrainy. (2001). Kharkiv: RIREH, 376.

7. Tabart, J., Kevers, C., Evers, D., Dommes, J. (2011). Ascorbic Acid, Phenolic Acid, Flavonoid, and Carotenoid Profiles of Selected Extracts from Ribes nigrum. Journal of Agricultural and Food Chemistry, 59 (9), 4763-4770. doi: http://doi.org/ $10.1021 / \mathrm{jf} 104445 \mathrm{c}$

8. Skotti, E., Anastasaki, E., Kanellou, G., Polissiou, M., Tarantilis, P. A. (2014). Total phenolic content, antioxidant activity and toxicity of aqueous extracts from selected Greek medicinal and aromatic plants. Industrial Crops and Products, 53, 46-54. doi: http://doi.org/10.1016/j.indcrop.2013.12.013

9. Romanenko, Y. A., Koshovyi, O. M., Komissarenko, A. M., Golembiovska, O. I., Gladyish, Y. I. (2018). The study of the chemical composition of the components of the motherwort herb. Newes of Pharmacy, 3 (95), 34-38. doi: http://doi.org/ 10.24959/nphj.18.2222

10. Simonovska, B., Vovk, I., Andrenšek, S., Valentová, K., Ulrichová, J. (2003). Investigation of phenolic acids in yacon (Smallanthus sonchifolius) leaves and tubers. Journal of Chromatography A, 1016 (1), 89-98. doi: http://doi.org/10.1016/ s0021-9673(03)01183-x

11. Liu, F. F., Ang, C. Y. W., Springer, D. (2000). Optimization of Extraction Conditions for Active Components inHypericum perforatumUsing Response Surface Methodology. Journal of Agricultural and Food Chemistry, 48 (11), 5788-5788. doi: http://doi.org/10.1021/jf001124y

Anna Krvavych, PhD, Assistant, Department of Technology of Biologically Active Substances, Pharmacy and Biotechnology, Lviv Polytechnic National University, Lviv, Ukraine, ORCID: https://orcid.org/ 0000-0002-7402-2689, e-mail: anna.s.krvavych@lpnu.ua

Roksolana Konechna, PhD, Associate Professor, Department of Technology of Biologically Active Substances, Pharmacy and Biotechnology. Lviv Polytechnic National University, Lviv, Ukraine, ORCID: https:// orcid.org/0000-0001-6420-9063, e-mail: rkonechna@ukr.net 